\title{
Activation of Adenylate Cyclase by Heat-Labile Escherichia Coli Enterotoxin
}

\author{
EVIDENCE FOR ADP-RIBOSYLTRANSFERASE ACTIVITY \\ SIMILAR TO THAT OF CHOLERAGEN
}

\author{
Joel Moss, Laboratory of Cellular Metabolism, National Heart, Lung, and Blood \\ Institute, National Institutes of Health, Bethesda, Maryland 20014 \\ STEPHEN H. RICHARDSON, Department of Microbiology and Immunology, Bowman \\ Gray School of Medicine, Wake Forest University, Winston-Salem, \\ North Carolina 27103
}

A B S T RACT Highly purified, polymyxin-released, low molecular weight Escherichia coli heat-labile enterotoxin (LT) catalyzed the hydrolysis of NAD to ADP-ribose and nicotinamide. This NAD glycohydrolase activity was stimulated by dithiothreitol and was independent of cellular components. Nicotinamide formation was enhanced by arginine methyl ester $>$ D-arginine $\cong$ L-arginine $\cong$ guanidine. A 20 -fold increase in activity was noted with arginine methyl ester, and maximal activity again required dithiothreitol. When the reaction was initiated with toxin, a delay was observed before a constant rate was established. The reaction products found after incubation of [adenine-U- $\left.{ }^{14} \mathrm{C}\right] \mathrm{NAD}$ and $\mathrm{L}-\left[{ }^{3} \mathrm{H}\right]$ arginine or unlabeled arginine methyl ester with the enterotoxin had mobilities on thin-layer chromatograms similar to the reaction products obtained after incubation of choleragen with these substrates and are consistent with the formation of ADP-ribose-L-arginine and ADP-riboseL-arginine methyl ester, respectively. Both toxins, which catalyze the NAD-dependent activation of adenylate cyclase, thus appear to possess NAD glycohydrolase and ADP-ribosyltransferase activities. Although the activities of both toxins are dependent on dithiothreitol, Escherichia coli enterotoxin exhibited optimal activity in $\operatorname{Tris}\left(\mathrm{Cl}^{-}\right)(\mathrm{pH} 7.5)$ and was inhibited by high concentrations of potassium phosphate (pH 7.0) or low $\mathrm{pH}$ (sodium acetate, $\mathrm{pH}$ 6.2). It appears

Portions of this work were presented at the meetings of the American Society of Biological Chemists, 4-8 June 1978, in Atlanta, Ga. and the American Society for Microbiology, 14-19 May 1978, in Las Vegas, Nev.

Received for publication 2 February 1978 and in revised form 5 April 1978. that the optimal assay conditions as well as the kinetic constants for the reactants differ from those previously noted with choleragen. It is probable therefore that although the two toxins catalyze similar reactions, they differ in primary structure. The presence of transferase and glycohydrolase activities in structurally distinct toxins that activate adenylate cyclase strengthens our hypothesis that the ADP-ribosylation of arginine is a model for the NAD-dependent activation of adenylate cyclase; activation may result from ADP-ribosylation of the cyclase itself or of a protein that regulates its activity.

\section{INTRODUCTION}

Certain strains of Escherichia coli produce a heatlabile enterotoxin (LT), ${ }^{1}$ which is believed to be responsible for the syndrome characteristic of "traveler's diarrhea" (1-5). The effects of the toxin are a result of the intracellular accumulation of cyclic AMP and activation of adenylate cyclase (6-13); Gill et al. (13), with a cell-free system derived from pigeon erythrocytes, have shown that the toxin activates adenylate cyclase in a process that is dependent upon NAD and ATP. Thus, the biochemical effects of the toxin are similar to those of choleragen (cholera toxin), an enterotoxin of Vibrio cholerae, which also causes the NADdependent activation of adenylate cyclase $(14,15)$. Although the mechanism of choleragen activation and NAD utilization has not been determined, it has been demonstrated (16-18) that both the holotoxin and its A protomer can catalyze the hydrolysis of NAD to ADP-

${ }^{1}$ Abbreviation used in this paper: LT, Escherichia coli heat-labile enterotoxin. 
ribose and nicotinamide (reaction [1]) and the transfer of the ADP-ribose moiety of NAD to arginine (reaction [2]). Because reaction (1) is analogous to that

$$
\begin{aligned}
\text { NAD } & \rightarrow \text { ADP-ribose } \\
& \left.+ \text { nicotinamide }+\mathrm{H}^{+} \text {(NAD glycohydrolase }\right) \\
\text { NAD } & + \text { arginine } \rightarrow \text { ADP-ribose-L-arginine } \\
& \left.+ \text { nicotinamide }+\mathrm{H}^{+} \text {(ADP-ribosyltransferase }\right)
\end{aligned}
$$

catalyzed by diphtheria toxin (19), which inhibits protein synthesis as a result of the ADP-ribosylation of elongation factor II (20), and because choleragen catalyzes the ADP-ribosylation of an amino acid, it was proposed that choleragen activation of adenylate cyclase involves the ADP-ribosylation of the cyclase itself or of a regulatory protein (17). If choleragen and LT activate adenylate cyclase through similar mechanisms, and if the ADP-ribosylation of arginine in the presence of choleragen is, in fact, a model for the reaction critical to the activation process, then it would be presumed that LT should also catalyze reactions (1) and (2). We report here that a polymyxin-released LT of low mol wt $(\cong 20,000)$ possesses both NAD glycohydrolase and ADP-ribosyltransferase activities. Furthermore, although LT and choleragen are apparently immunologically related $(13,21-27)$, they exhibit different requirements for the optimal expression of catalytic activity.

\section{METHODS}

NAD glycohydrolase and ADP-ribosyltransferase assays. NAD glycohydrolase and ADP-ribosyltransferase activities were assayed in a total volume of $150 \mu \mathrm{l}$ containing $2 \mathrm{mM}$ [carbonyl $-{ }^{14} \mathrm{C}$ ]NAD ( $\left.\cong 40,000 \mathrm{cpm}\right), 20 \mathrm{mM}$ dithiothreitol, and $50 \mathrm{mM}$ potassium phosphate $(\mathrm{pH} 7.0)$ in the absence and presence of $75 \mathrm{mM}$ arginine methyl ester, respectively. Substitutions were made in the assay as noted in legends for tables and figures. Assays were initiated with the addition of LT and incubated for $5 \mathrm{~h}$ at $30^{\circ} \mathrm{C}$. Two $0.05-\mathrm{ml}$ samples from each assay were than transferred to columns of AG 1-X2 (Bio-Rad Laboratories, Richmond, Calif.) from which [carbonyl$\left.{ }^{14} \mathrm{C}\right]$ nicotinamide was eluted for radioassay (16). All assays were run in duplicate.

Purification of LT. The polymyxin-released LT was purified by procedures described previously (28) plus an additional step involving gel filtration on Ultrogel AcA-44 (LKB Instruments, Inc., Rockville, Md.). This toxin, which was previously shown to be of low mol wt $(\cong 20,000)$, exhibited on polyacrylamide gels one major band with biological activity.

Materials. The sources of the materials used in the assays of NAD glycohydrolase and ADP-ribosyltransferase and the specific activities of the radioactive substrates have been described (16-18). Protein was determined by the method of Lowry et al. (29).

\section{RESULTS}

The highly purified, polymyxin-released LT catalyzed the formation of $\left[\right.$ carbonyl- $\left.{ }^{14} \mathrm{C}\right]$ nicotinamide from
TABLE I

Effect of Dithiothreitol and Arginine Methyl Ester on $\left[\right.$ Carbonyl- ${ }^{14} \mathrm{C}$ ]Nicotinamide Formation from [Carbonyl $\left.-{ }^{14} \mathrm{C}\right] N A D$ Catalyzed by $L T$

\begin{tabular}{lc}
\hline \multicolumn{1}{c}{ Additions } & $\begin{array}{c}\text { Nicotinamide } \\
\text { formed }\end{array}$ \\
\hline & $n$ mol/5 h \\
None & 0.1 \\
Dithiothreitol, $20 \mathrm{mM}$ & 1.7 \\
Arginine methyl ester, $75 \mathrm{mM}$ & 2.1 \\
Arginine methyl ester and dithiothreitol & 28.8 \\
Arginine methyl ester, dithiothreitol, and 400 & \\
$\quad$ mM potassium phosphate & 12.4 \\
\hline
\end{tabular}

Assays containing $2 \mathrm{mM}$ [carbonyl $\left.-{ }^{14} \mathrm{C}\right] \mathrm{NAD}(41,000 \mathrm{cpm})$ and $50 \mathrm{mM}$ potassium phosphate, $\mathrm{pH} 7.0$ (except as indicated), in a total volume of $0.15 \mathrm{ml}$ were initiated with the addition of LT $(107 \mu \mathrm{g})$.

NAD (Table I). The reaction was stimulated by dithiothreitol and arginine methyl ester and was inhibited by high concentrations of potassium phosphate $(\mathrm{pH}$ 7.0) (Table I). In assays containing potassium phosphate, arginine methyl ester, and dithiothreitol, and initiated with LT, there was a delay of at least $30 \mathrm{~min}$ before the maximal rate of nicotinamide production

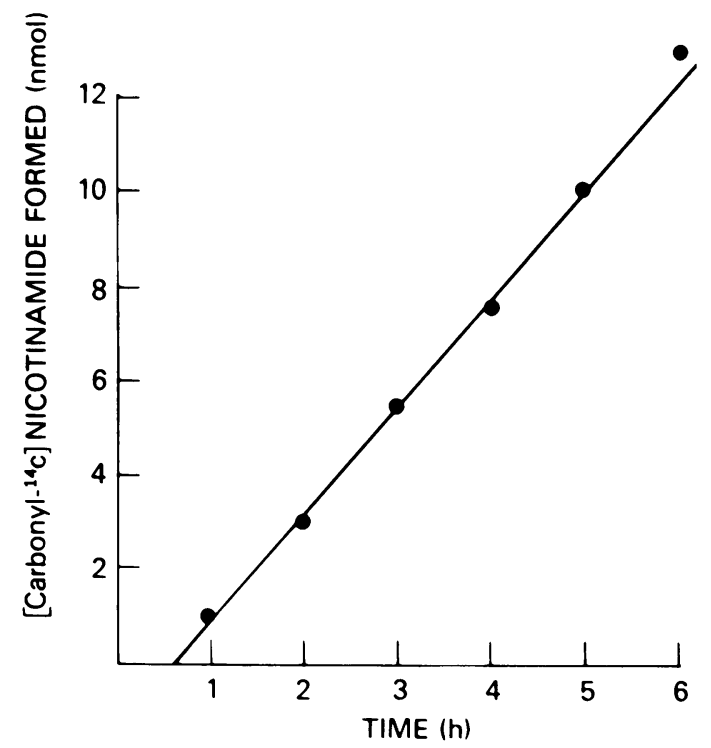

FIGURE 1 Formation of [carbonyl $\left.-{ }^{14} \mathrm{C}\right]$ nicotinamide from [carbonyl $\left.-{ }^{14} \mathrm{C}\right] \mathrm{NAD}$ catalyzed by LT. Assays were initiated with the addition of LT $(107 \mu \mathrm{g})$ and contained $50 \mathrm{mM}$ potassium phosphate, $20 \mathrm{mM}$ dithiothreitol, $2 \mathrm{mM}$ [carbonyl $-{ }^{14} \mathrm{C}$ ]NAD $\left(2.2 \times 10^{5} \mathrm{cpm}\right)$, and $75 \mathrm{mM}$ arginine methyl ester in a total volume of $0.75 \mathrm{ml}$. At the indicated times, two $0.05-\mathrm{ml}$ samples were transferred to columns of AG 1-X2 for separation of nicotinamide. Data are the means of values from duplicate incubations for $\left[\right.$ carbonyl $\left.-{ }^{14} \mathrm{C}\right]$ nicotinamide formation per $0.05-\mathrm{ml}$ sample. 


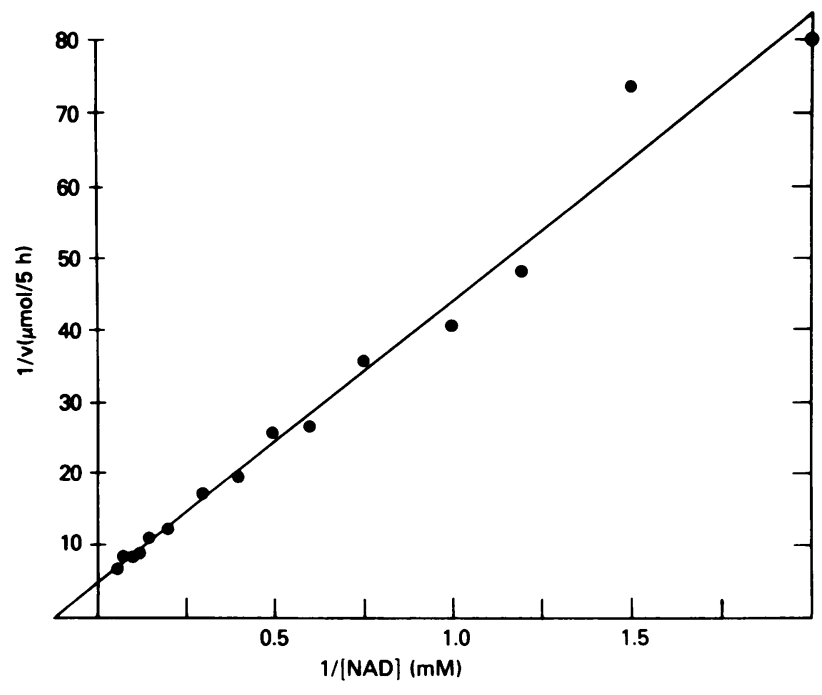

Figure 2 Determination of the $K_{m}$ for NAD under the standard assay conditions for LT. Assays were carried out as described in Methods with $107 \mu \mathrm{g}$ of LT and $75 \mathrm{mM}$ arginine methyl ester except that the NAD concentration was varied as indicated. Each assay contained $\cong 42,300 \mathrm{cpm}$ of [carbonyl- $\left.{ }^{14} \mathrm{C}\right] \mathrm{NAD}$.

was established; the rate was then constant for over $5 \mathrm{~h}$ (Fig. 1). As shown in Fig. 2, the $K_{m}$ for NAD under these conditions was $8 \mathrm{mM}$. At $\mathrm{pH} 7.5$ (Tris buffer) nicotinamide production in the presence of arginine methyl ester was greater than it was at $\mathrm{pH} 8$ (Tris or glycine buffer) or at $\mathrm{pH} 7.0$ (phosphate buffer). At $\mathrm{pH}$ 6.2 (acetate) nicotinamide production was only $10 \%$ of that at $\mathrm{pH} 7.5$ (Table II).

In addition to arginine methyl ester, which increased nicotinamide formation 20 -fold, L-arginine, D-arginine,

TABLE II

Effect of Buffers and $p H$ on [Carbonyl- $\left.{ }^{14} \mathrm{C}\right]$ Nicotinamide

Formation from $\left[\right.$ Carbonyl $\left.-{ }^{14} \mathrm{C}\right] \mathrm{NAD}$ in the Presence of Arginine Methyl Ester Catalyzed by LT

\begin{tabular}{cc}
\hline Buffer $(50 \mathrm{mM})$ & Nicotinamide formed \\
\hline & nmol/5 $h$ \\
Sodium acetate & \\
pH 6.2 & 5.1 \\
Potassium phosphate & \\
pH 6.5 & 17.4 \\
pH 7.0 & 40 \\
Tris $\left(\mathrm{Cl}^{-}\right)$ & \\
pH 7.5 & 52 \\
pH 8.0 & 35 \\
Glycine $(\mathrm{HCl})$ & \\
pH 8.0 & 41 \\
pH 8.5 & 23
\end{tabular}

Assays were carried out as described in Methods with 107 $\mu \mathrm{g}$ of LT, $75 \mathrm{mM}$ arginine methyl ester, and buffer as indicated.
TABLE III

Effect of Amino Acids and Related Compounds on Formation of [Carbonyl $\left.-{ }^{14} \mathrm{C}\right]$ Nicotinamide from [Carbonyl-

$\left.{ }^{14} \mathrm{C}\right] N A D$ Catalyzed by $L T$

\begin{tabular}{lc}
\hline \multicolumn{1}{c}{ Additions $(\mathbf{7 5} \mathrm{mM})$} & Nicotinamide formed \\
\hline & $n$ mol/5 $\boldsymbol{h}$ \\
None & 1.9 \\
Arginine methyl ester & 40.0 \\
Lysine & 2.5 \\
L-Arginine & 17.0 \\
D-Arginine & 22.0 \\
Guanidine & 21.0 \\
Histidine & 2.1 \\
Urea & 2.1 \\
Citrulline & 1.5 \\
Serine & 2.0 \\
\hline
\end{tabular}

Assays were carried out as described in Methods with 107 $\mu \mathrm{g}$ of LT and other additions as indicated.

and guanidine were also effective, although to a lesser degree, in stimulating the reaction (Table III). The $K_{a}$ for both arginine methyl ester and arginine was $240 \mathrm{mM}$, but the $V_{\max }$ in the presence of arginine methyl ester was twice that with arginine (Fig. 3). Lysine, citrulline, histidine, and serine were ineffective (Table III).

Formation of ADP-ribose-L-arginine and ADPribose-L-arginine methyl ester. After incubation of [adenine- $\left.\mathrm{U}-{ }^{14} \mathrm{C}\right] \mathrm{NAD}$ and $\mathrm{L}-\left[{ }^{3} \mathrm{H}\right]$ arginine or arginine methyl ester with choleragen, the reaction products

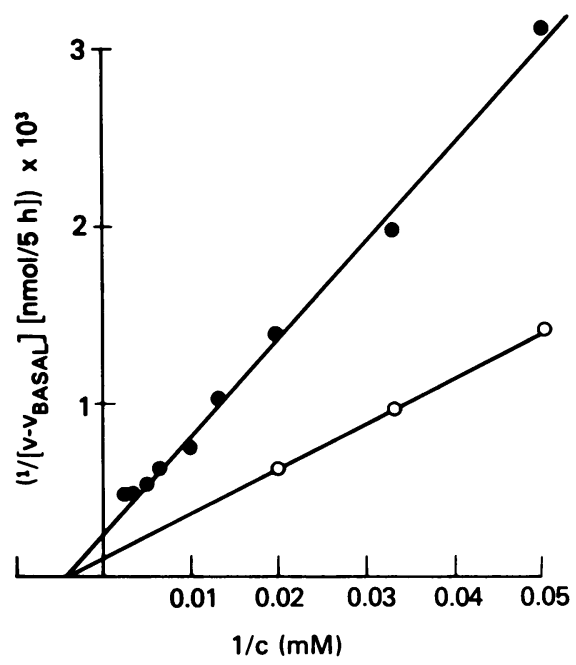

FIGURE 3 Determination of the $K_{a}$ for arginine and arginine methyl ester. Assays with $37 \mu \mathrm{g}$ of LT were carried out as described in Methods except that the concentration of NAD was $8 \mathrm{mM}(\cong 43,700 \mathrm{cpm})$ and the concentrations (c) of arginine $(O)$ or arginine methyl ester $(O)$ were varied as indicated. $\mathrm{V}_{\text {basal }}=\mathrm{nmol}$ of $\left[\right.$ carbonyl $\left.-{ }^{14} \mathrm{C}\right]$ nicotinamide formed in the absence of arginine or arginine methyl ester $=155 \mathrm{nmol}$, i.e., less than $10 \%$ of the maximum observed with arginine. 
can be separated from ADP-ribose, NAD and arginine, or arginine methyl ester by thin-layer chromatography with isobutyric acid: $\mathrm{NH}_{4} \mathrm{OH}: \mathrm{H}_{2} \mathrm{O}, 66: 1: 33$, on DEAEcellulose or cellulose, respectively (17). After incubations with LT, reaction products with identical mobilities in both systems were observed. The compounds formed in the presence of either LT or choleragen contained ${ }^{14} \mathrm{C}$ (and ${ }^{3} \mathrm{H}$, where $\mathrm{L}-\left[{ }^{3} \mathrm{H}\right]$ arginine was present), reacted with ninhydrin and quenched the background fluorescence of plates viewed in ultraviolet light. These results are consistent with the formation of an ADP-ribose-L-arginine product catalyzed by both LT and choleragen. As expected, the formation of the ADP-ribose-L-arginine derivative was associated with the formation of $\left[\right.$ carbonyl $\left.-{ }^{14} \mathrm{C}\right]$ nicotinamide as demonstrated in parallel experiments with [carbonyl$\left.{ }^{14} \mathrm{C}\right]$ NAD and unlabeled arginine or arginine methyl ester as substrates. Thus, as has been previously noted with choleragen (17), LT appears to be capable of transferring the ADP-ribosyl moiety of NAD to L-arginine to yield ADP-ribose-L-arginine with release of free nicotinamide and $\mathrm{H}^{+}$.

\section{DISCUSSION}

Several bacterial toxins require NAD for their effects on animal cells. The best investigated of these are diphtheria and Pseudomonas toxins, which catalyze the transfer of the ADP-ribose moiety of NAD to an acceptor protein, elongation factor II $(20,30)$. This protein is necessary for protein synthesis, and its ADPribosylation results in inhibition of the process. Like these toxins, both choleragen (an enterotoxin of Vibrio cholerae) and LT require NAD $(13,14)$; they, however, appear to exert their effects on cells by activating adenylate cyclase. Although the role of NAD in adenylate cyclase activation has not been defined, it has been shown that choleragen can catalyze the hydrolysis of NAD to ADP-ribose and nicotinamide (16-18), a reaction analogous to the abortive reaction catalyzed by both diphtheria and Pseudomonas toxins $(19,31)$. In addition, choleragen will catalyze the transfer of the ADP-ribose moiety of NAD to arginine (17). In view of the NAD requirement for choleragen action, as well as the facts that choleragen can hydrolyze NAD and transfer the ADP-ribose moiety of NAD to a basic amino acid, which could serve as a model for an acceptor amino acid in the acceptor protein, it was proposed that choleragen activation of adenylate cyclase proceeded by the ADP-ribosylation of the cyclase itself or a protein critical to cyclase activation. The protein acceptor for the ADP-ribose of NAD in the choleragencatalyzed reaction has not been identified.

We have now shown that a heat-labile, low molecular weight toxin isolated from $E$. coli, which causes both the NAD-dependent activation of adenylate cyclase in cell-free pigeon erythrocyte preparations (13) and accumulation of intracellular cyclic AMP $(6,7)$, possesses both NAD glycohydrolase and ADP-ribosyltransferase activities. The polymyxin-released LT thus appears to be functionally equivalent to choleragen. Other investigators have reported that antibodies to choleragen will cross-react with LT (13, 21-27). As noted here, however, the requirements for demonstration of optimal ADP-ribosyltransferase activity of LT differ considerably from those observed with choleragen. Whereas choleragen activity was enhanced over eightfold by increasing the potassium phosphate concentration from $50 \mathrm{mM}$ to $400 \mathrm{mM}$ (16), LT was inhibited by more than $50 \%$. Sodium acetate ( $\mathrm{pH} 6.2$ ) was as good a buffer as potassium phosphate for choleragen (16), although it inhibited LT activity by over $80 \%$. Indeed, Tris $\left(\mathrm{Cl}^{-}\right)$, pH 7.5, which was a poor buffer for choleragen gave excellent ADP-ribosyltransferase activity with LT. The $K_{m}$ for NAD and the $K_{a}$ for arginine were higher for LT than for choleragen. It appears, therefore, that although both toxins catalyze similar reactions, require thiol, exhibit a lag in reaction rate, and are immunologically similar, they may differ in structure. The fact that the ability to catalyze the transferase and glycohydrolase reactions is preserved in structurally distinct toxins which activate adenylate cyclase lends further support to the theory that the ADP-ribosylation of arginine, or similar amino acid, may be critical to toxin action. As proposed earlier (17), the transferase reaction would serve as a model for the ADP-ribosylation of the cyclase or of its regulatory protein.

\section{ACKNOWLEDGMENTS}

We thank Dr. Martha Vaughan for many useful discussions and critical review of the manuscript, and Miss Sally J. Stanley for expert technical assistance.

This work was supported in part by a grant to Dr. Stephen H. Richardson, grant no. AI-07772, from the U. S.-Japan Cooperative Medical Scientist Program, National Institute of Allergy and Infectious Diseases, National Institutes of Health.

\section{REFERENCES}

1. Rowe, B., J. Taylor, and K. A. Bettleheim. 1970. An investigation of travellers' diarrhoea. Lancet I: 1-5.

2. Shore, E. G., A. G. Dean, K. J. Holik, and B. R. Davis. 1974. Enterotoxin-producing Escherichia coli and diarrheal disease in adult travelers: a prospective study. J. Infect. Dis. 129: 577-582.

3. Gorbach, S. L., B. H. Kean, D. G. Evans, D. J. Evans, Jr., and D. Bessudo. 1975. Travelers' diarrhea and toxigenic Escherichia coli. N. Engl. J. Med. 292: 933-936.

4. Merson, M. H., G. K. Morris, D. A. Sack, J. G. Wells, J. C. Feeley, R. B. Sack, W. B. Creech, A. Z. Kapikian, and E. J. Gangarosa. 1976. Travelers' diarrhea in Mexico. A prospective study of physicians and family members attending a congress. N. Engl. J. Med. 294: 1299-1305.

5. Sack, D. A., D. C. Kaminsky, R. B. Sack, I. A. Wamola, F. Orskov, I. Ørskov, R. C. B. Slack, R. R. Arthur, and A. Z. Kapikian. 1977. Enterotoxigenic Escherichia coli 
diarrhea of travelers: a prospective study of American Peace Corps volunteers. Johns Hopkins Med. J. 141: 63-70.

6. Zenser, T. V., and J. F. Metzger. 1974. Comparison of the action of Escherichia coli enterotoxin on the thymocyte adenylate cyclase-cyclic adenosine monophosphate system to that of cholera toxin and prostaglandin $E_{1}$. Infect. Immun. 10: 503-509.

7. Mashiter, K., G. D. Maishiter, R. L. Hauger, and J. B. Field. 1973. Effects of cholera and $E$. coli enterotoxins on cyclic adenosine $3^{\prime}, 5^{\prime}$-monophosphate levels and intermediary metabolism in the thyroid. Endocrinology. 92: 541-549.

8. Kantor, H. S., P. Tao, and S. L. Gorbach. 1974. Stimulation of intestinal adenyl cyclase by Escherichia coli enterotoxin: comparison of strains from an infant and an adult with diarrhea. J. Infect. Dis. 129: 1-9.

9. Hynie, S., H. Rašková, T. Sechser, J. Vaněček, D. Matějovská, V. Matějovská, M. Treu, and L. Polák. 1974. Stimulation of intestinal and liver adenyl cyclase by enterotoxin from strains of Escherichia coli enteropathogenic for calves. Toxicon. 12: 173-179.

10. Evans, D. J., Jr., L. C. Chen, G. T. Curlin, and D. G. Evans. 1972. Stimulation of adenyl cyclase by Escherichia coli enterotoxin. Nat. New Biol. 236: 137-138.

11. Dorner, F., and P. Mayer. 1975. Escherichia coli enterotoxin: stimulation of adenylate cyclase in broken-cell preparations. Infect. Immun. 11: 429-435.

12. Hewlett, E. L., R. L. Guerrant, D. J. Evans, Jr., and W. B. Greenough III. 1974. Toxins of Vibrio cholerae and Escherichia coli stimulate adenyl cyclase in rat fat cells. Nature (Lond.). 249: 371-373.

13. Gill, D. M., D. J. Evans, Jr., and D. G. Evans. 1976. Mechanism of activation of adenylate cyclase in vitro by polymyxin-released, heat-labile enterotoxin of Escherichia coli. J. Infect. Dis. 133 (Suppl): S103-S107.

14. Gill, D. M. 1975. Involvement of nicotinamide adenine dinucleotide in the action of cholera toxin in vitro. Proc. Natl. Acad. Sci. U. S. A. 72: 2064-2068.

15. Gill, D. M. 1976. Multiple roles of erythrocyte supernatant in the activation of adenylate cyclase by Vibrio cholerae toxin in vitro. J. Infect. Dis. 133 (Suppl): S55-S63.

16. Moss, J., V. C. Manganiello, and M. Vaughan. 1976. Hydrolysis of nicotinamide adenine dinucleotide by choleragen and its A protomer: possible role in the activation of adenylate cyclase. Proc. Natl. Acad. Sci. U. S. A. 73: 4424-4427.

17. Moss, J., and M. Vaughan. 1977. Mechanism of action of choleragen. Evidence for ADP-ribosyltransferase activity with arginine as an acceptor. J. Biol. Chem. 252: 2455-2457.
18. Moss, J., J. C. Osborne, Jr., P. H. Fishman, H. B. Brewer, Jr., M. Vaughan, and R. O. Brady. 1977. Effect of gangliosides and substrate analogues on the hydrolysis of nicotinamide adenine dinucleotide by choleragen. Proc. Natl. Acad. Sci. U. S. A. 74: 74-78.

19. Kandel, J., R. J. Collier, and D. W. Chung. 1974. Interaction of fragment $A$ from diphtheria toxin with nicotinamide adenine dinucleotide. J. Biol. Chem. 249: 20882097.

20. Honjo, T., Y. Nishizuka, O. Hayaishi, and I. Kato. 1968. Diphtheria toxin-dependent adenosine diphosphate ribosylation of aminoacyl transferase II and inhibition of protein synthesis. J. Biol. Chem. 243: 3553-3555.

21. Gyles, C. L., and D. A. Barnum. 1969. A heat-labile enterotoxin from strains of Escherichia coli enteropathogenic for pigs. J. Infect. Dis. 120: 419-426.

22. Smith, N. W., and R. B. Sack. 1973. Immunologic crossreactions of enterotoxins from Escherichia coli and Vibrio cholerae. J. Infect. Dis. 127: 164-170.

23. Holmgren, J., O. Söderlind, and T. Wadström. 1973. Cross-reactivity between heat labile enterotoxins of Vibrio cholerae and Escherichia coli in neutralization tests in rabbit ileum and skin. Acta Pathol. Microbiol. Scand. Sect. B. Microbiol. Immunol. 81: 757-782.

24. Gyles, C. L. 1974. Relationships among heat-labile enterotoxins of Escherichia coli and Vibrio cholerae. J. Infect. Dis. 129: 277-283.

25. Gyles, C. L. 1974. Immunological study of the heat-labile enterotoxins of Escherichia coli and Vibrio cholerae. Infect. Immun. 9: 564-570.

26. Kwan, C. N., and R. M. Wishnow. 1974. Esherichia coli enterotoxin-induced steroidogenesis in cultured adrenal tumor cells. Infect. Immun. 10: 146-151.

27. Klipstein, F. A., and R. F. Engbert. 1977. Immunological interrelationships between cholera toxin and the heatlabile and heat-stable enterotoxins of coliform bacteria. Infect. Immun. 18: 110-117.

28. Evans, D. J., Jr., D. G. Evans, S. H. Richardson, and S. L. Gorbach. 1976. Purification of the polymyxin-released, heat-labile enterotoxin of Escherichia coli. J. Infect. Dis. 133 (Suppl): S97-S102.

29. Lowry, O. H., N. J. Rosebrough, A. L. Farr, and R. J. Randall. 1951. Protein measurement with the Folin phenol reagent. J. Biol. Chem. 193: 265-275.

30. Iglewski, B. H., and D. Kabat. 1975. NAD-dependent inhibition of protein synthesis by Pseudomonas aeruginosa toxin. Proc. Natl. Acad. Sci. U. S. A. 72: 2284-2288.

31. Chung, D. W., and R. J. Collier. 1977. Enzymatically active peptide from the adenosine diphosphate-ribosylating toxin of Pseudomonas aeruginosa. Infect. Immun. 16: $832-841$. 